\title{
Association between TIMP-2 gene polymorphism and breast cancer in Han Chinese women
}

\author{
Kai Wang ${ }^{1,2}$, Guanying Wang ${ }^{1}$, Shangke Huang ${ }^{1}$, Anqi Luo ${ }^{1}$, Xin Jing ${ }^{1}$, Gang Li ${ }^{3}$, Yi Zhou ${ }^{4}$ and Xinhan Zhao ${ }^{1 *}$ (D)
}

\begin{abstract}
Background: TIMP-2 gene plays an important role in the development of breast cancer. The present study was conducted to evaluate whether TIMP-2 gene polymorphisms are associated with breast cancer risk in a Han Chinese cohort.

Methods: Six single nucleotide polymorphisms (SNPs) within the TIMP-2 gene in 571 breast cancer and 578 healthy control subjects were genotyped through the Agena MassARRAY. Logistic regression analysis was used to assess the influence of TIMP-2 polymorphisms on breast cancer. Functional annotation of TIMP-2 variants and TIMP-2 expression were analyzed by bioinformatics.

Results: Bioinformatics analysis found that rs4789936 was likely to affect transcription factor binding, motifs, DNase footprint, and DNase peaks; and TIMP-2 was under-expressed in breast cancer, the risk allele of rs4789936 was associated with increased expression of TIMP-2 in peripheral blood samples. Importantly, individuals carrying TIMP-2 rs2277698 T allele have a 19\% lower risk of breast cancer than individuals with allele C, providing protection (OR $=0.81$, $95 \% \mathrm{Cl}=0.67-0.99, p=0.041)$. In the breast cancer patients with c-erb positive and PR positive, when the CC genotype was used as a reference, individuals carrying the $\Pi$ genotype increased the risk of breast cancer. Haplotype analysis showed "TCC" was associated with a reduced risk of breast cancer $(\mathrm{OR}=0.79,95 \% \mathrm{Cl}=0.63-0.97, p=0.028)$.
\end{abstract}

Conclusion: Our study indicated that TIMP-2 rs2277698 was associated with breast cancer susceptibility.

Keywords: Breast cancer, TIMP-2, Gene polymorphism, Case-control study

\section{Background}

As one of the most prevalent malignancies with highly invasive and metastatic potential, breast cancer continues to be a major global health concern that leads to increasing morbidity and mortality among women worldwide [1]. Domestic and foreign scholars believe that extracellular matrix (ECM) plays a vital role in the invasion and migration of breast cancer cells [2]. Additionally, these studies have demonstrated that degradation of the basement membrane ECM is critical for the progression of tumorigenesis and metastasis [3]. Matrix metalloproteinase-2 (MMP-2) degrades type IV collagen, which is one of the major structural components of the

\footnotetext{
*Correspondence: zhaohanxin21@163.com

1 Department of Internal Medicine Oncology, The First Affiliated Hospital of Xi'an Jiaotong University, \#277 West Yanta Road, Xi'an 710061, Shaanxi, China Full list of author information is available at the end of the article
}

basement membrane ECM. Based on this function, MMP-2 is considered a crucial enzyme in the regulation of tumor proliferation and metastasis [4]. Previous studies have shown that $M M P-2$ expression is elevated in cancer patients compared with control subjects and is associated with advanced stages of disease and worse prognosis [5].

Tissue inhibitor of metalloproteinase-2 (TIMP-2) is an endogenous inhibitor of MMP-2 that has been implicated in the regulation of MMP-2 proteolytic activity through formation of a 1:1 stoichiometric inhibitory complex with the enzyme [6]. Genetic polymorphisms in the TIMP-2 gene, located on chromosome $17 \mathrm{q} 25$, may lead to an increase or decrease in TIMP-2 activity and subsequently disrupt the balance between the activity of TIMP-2 and MMP-2. This disrupted balance could then influence cancer development and progression [7]. More

(c) The Author(s). 2019 Open Access This article is distributed under the terms of the Creative Commons Attribution 4.0 International License (http://creativecommons.org/licenses/by/4.0/), which permits unrestricted use, distribution, and reproduction in any medium, provided you give appropriate credit to the original author(s) and the source, provide a link to the Creative Commons license, and indicate if changes were made. The Creative Commons Public Domain Dedication waiver (http://creativecommons.org/publicdomain/zero/1.0/) applies to the data made available in this article, unless otherwise stated. 
and more research have shown that TIMP-2 mutation influence the risk of the development and persistence of numerous carcinomas and diseases [8-12]. The correlation between the genetic variants of TIMP-2 and susceptibility to stroke [13], oral squamous cell carcinoma [8], prostate cancer [9], abdominal aortic aneurysm [10], head and neck squamous cell carcinoma [11], and gastric cancer [12] have been identified in a number of studies worldwide. Taken together, these findings suggest that evaluation of TIMP-2 polymorphism in cancers may be useful as a prognostic indicator.

Very few studies have evaluated polymorphism of TIMP-2 in individuals with breast cancer. Combining with the existing literature reports, and minor allele frequencies (MAFs) of greater than 5\% in the global population, we selected rs2277698, rs2009196, rs7342880, rs11654470, rs2003241, and rs4789936 six SNPs to research the effect of TIMP-2 gene polymorphisms on the susceptibility of breast cancer in a cohort of Han Chinese women. Genetic screening involving polymorphism of the TIMP-2 gene could provide valuable information for breast cancer susceptibility and identification of high risk patients.

\section{Methods}

\section{Study participants}

From the First Affiliated Hospital of Xi'an Jiaotong University, we recruited 571 breast cancer patients (mean age: $50.91 \pm 11.23$ years), which were recently diagnosed, histologically confirmed, presented without any previous acute or chronic pathology. We also recorded some clinical information about patients from the patients' medical records, as shown in Table 1. Consist of smoking and drink status, tumor size, clinical stages, Lymph node metastasis (Yes, or No), menopausal status (Yes, or No), procreative times, estrogen receptor (ER) status (Positive or negative), progesterone receptor (PR) status (Positive or negative), and c-erbB status (Positive or negative). At the same time 578 healthy subjects (mean age: 49.22 \pm 10.11 years) were recruited from a large cohort of Han Chinese women, the Controls were generally healthy without diseases related to the vital organs.

\section{SNP selection and genotyping}

We selected the GoldMag-Mini Whole Blood Genomic DNA Purification Kit (GoldMag Co. Ltd. Xi'an City, China) to extract the DNA from the $5 \mathrm{ml}$ peripheral venous blood; and Nanodrop 2000 (Gene Company Limited) was used to detect the concentration and purity of samples, DNA to ensure that the samples could be used for subsequent experiments. Same as previously published articles [14, 15]. rs2277698, rs2009196, rs7342880, rs11654470, rs2003241, and rs4789936 Six SNPs were selected in our study based on minor allele frequency data more than 0.05 in the global population [16]. Primer design and SNP typing were
Table 1 The characteristics of breast cancer cases and cancerfree controls

\begin{tabular}{|c|c|c|c|}
\hline Characteristics & Cases & Control & $P$ value \\
\hline Number & 566 & 578 & \\
\hline Age $($ mean $\pm S D)$ & $50.91 \pm 11.23$ & $49.22 \pm 10.11$ & 0.017 \\
\hline \multicolumn{4}{|l|}{ smoking and drink } \\
\hline No & 328 & & \\
\hline Yes & 40 & & \\
\hline \multicolumn{4}{|l|}{ Age of menarche } \\
\hline$\leq 14$ & 145 & & \\
\hline$>14$ & 119 & & \\
\hline \multicolumn{4}{|l|}{ Menopausal status } \\
\hline Premenopausal & 104 & & \\
\hline Postmenopausal & 156 & & \\
\hline \multicolumn{4}{|l|}{ Procreative times } \\
\hline$<1$ & 104 & & \\
\hline$\geq 1$ & 130 & & \\
\hline \multicolumn{4}{|l|}{ Tumor size } \\
\hline$<2 \mathrm{~cm}$ & 105 & & \\
\hline$\geq 2 \mathrm{~cm}$ & 154 & & \\
\hline \multicolumn{4}{|l|}{ Tumor site } \\
\hline left & 256 & & \\
\hline right & 241 & & \\
\hline \multicolumn{4}{|c|}{ Lymph node involvement } \\
\hline Negative & 201 & & \\
\hline Positive & 197 & & \\
\hline \multicolumn{4}{|l|}{ Clinical stage } \\
\hline III-IV & 114 & & \\
\hline $\mid-\|$ & 272 & & \\
\hline \multicolumn{4}{|c|}{ Immunohistochemistry results } \\
\hline $\mathrm{ER}(-)$ & 108 & & \\
\hline ER $(+)$ & 208 & & \\
\hline PR $(-)$ & 145 & & \\
\hline $\mathrm{PR}(+)$ & 166 & & \\
\hline c-erb(-) & 91 & & \\
\hline c-erb(+) & 214 & & \\
\hline
\end{tabular}

$E R$ Estrogen receptor, $P R$ Progesterone receptor

performed in the same way as previously published articles $[14,15]$. The genotyping primers were designed with the Agena MassARRAY Assay Design 3.0 Software [17]. The Agena MassARRAY RS1000 was used for genotyping, and the related data were managed using Agena Typer 4.0 Software $[13,17,18]$.

\section{Bioinformatics and expression analyses}

To determine the effect of TIMP-2 SNPs on chromatin structure and allele-specific transcription factor binding, 
we used RegulomeDB [19] and HaploReg V4 [20]. The effect of mutation on TIMP-2 gene expressions in whole blood samples were further analyzed via the GTEX database (https://gtexportal.org/home/). Additionally, the UALCAN database [21] was used to analyze the expression of TIMP-2 in breast cancer tissues and normal tissues.

\section{Statistical analysis}

Demographic characteristics were counted. The Hardy-Weinberg equilibrium (HWE) was calculated by $X^{2}$ test [22]. Five genetic models were used to evaluate the association between gene polymorphisms and breast cancer risk. Odds ratios (ORs) and its corresponding 95\%CI were estimated using an logistic regression model with adjustments for age and gender through the PLINK software [23]. Further analysis to assess the impact of polymorphism on breast cancer based on tumor size, lymph node metastasis, ER/PR/ c-erb status, histological grade, procreative times, age of menarche and menopausal status. Linkage disequilibrium among polymorphic sites was assessed with Haploview [24], and associations between haplotypes and breast cancer risk were analyzed with PLINK version 1.07 software. The threshold of $p$ was set to 0.05 .

\section{Results}

Using RegulomeDB (Table 2), we found that rs4789936 was likely to affect transcription factor binding, motifs, DNase footprint, and DNase peaks. Additionally, rs2003241 was likely to affect transcription factor binding, motifs, and DNase peaks; whereas, the remaining genetic variants (rs2009196, rs7342880, and rs11654470) were only likely to affect transcription factor binding or DNase peaks. Consistent with these findings, HaploReg also predicted that rs2009196, rs7342880, rs1165447, rs2003241, and rs4789936 may result in motif changes (Table 2).

Table 3 shows the location, alleles of the TIMP-2 gene polymorphisms in the breast cancer group and the control group, and whether these sites satisfy the Hardy Weinberg equilibrium. Based on their deviation from
HWE, rs11654470 and rs2003241 were excluded from the subsequent analyses. Importantly, the frequencies of the rs 2277698 alleles were significantly different between breast cancer patients and control subjects, individuals carrying allele $\mathrm{T}$ have a $19 \%$ lower risk of breast cancer than individuals with allele $\mathrm{C}$, providing protection (OR $=0.81,95 \% \mathrm{CI}=0.67-0.99, p=0.041$ ).

The detailed findings of the logistic regression analysis for each genetic model are presented in Table 4. Of note, we observed that the frequency of the heterozygous variant C/T genotype of TIMP-2 rs2277698 was significantly reduced in breast cancer patients, when compared with healthy group. In the dominant model, after adjustment for age, the individuals with TIMP-2 rs2277698 CT + TT genotype have a $24 \%$ lower risk of developing breast cancer than $\mathrm{CC}$ genotype $(\mathrm{OR}=0.76,95 \% \mathrm{CI}=0.60-0.97$, $p=0.025)$.

As shown in Table 5 , in the breast cancer patients with c-erb positive and PR positive, when the TIMP-2 rs2277698 CC genotype was used as a reference, individuals carrying the TT genotype promoted the risk of breast cancer by 72 and $63 \%$ in allele model, respectively (c-erb positive: $\mathrm{OR}=1.72,95 \% \mathrm{CI}: 1.08-2.74, p=0.022$; PR positive: $\mathrm{OR}=1.63,95 \% \mathrm{CI}: 1.09-2.43, p=0.017$ ). When less than 49 years old, individuals with TT genotype had a $31 \%$ lower risk of breast cancer than the CC genotype individuals $(\mathrm{OR}=0.69,95 \% \mathrm{CI}: 0.52-0.9, p=$ 0.007).

Linkage analysis indicated that rs2277698, rs2009196, and rs7342880 exhibit extremely significant linkage disequilibrium (Fig. 1). Therefore, the haplotype frequencies of these SNPs were further examined for association with breast cancer (Table 6). Indeed, when the haplotype "CGC" used as a reference, the haplotype "TCC" was associated with a reduce ed. risk of breast cancer $(\mathrm{OR}=$ $0.79,95 \% \mathrm{CI}=0.63-0.97, p=0.028$ ).

To further validate our findings, we employed the use of two publically-available data sets. Examination of 1097 breast cancer tissues and 114 normal tissues from The Cancer Genome Atlas (TCGA) using the UALCAN database demonstrated that TIMP-2 was under-expressed in breast cancer tissues (Fig. 2a). The

Table 2 Functional annotation of TIMP-2 SNPs using RegulomeDB and HaploReg

\begin{tabular}{lllll}
\hline SNP & Gene & Allele & RegulomeDB & HaploReg \\
\hline rs2277698 (synonymous) & TIMP-2 & T/C & No Data & SiPhy conse, Selected eQTL hits \\
rs2009196 (intronic) & TIMP-2 & C/G & 5 & DNase, Motifs changed, Selected eQTL hits \\
rs7342880 (intronic) & TIMP-2 & A/C & 5 & DNase, Motifs changed, Selected eQTL hits \\
rs11654470 (intronic) & TIMP-2 & $\mathrm{C} / T$ & 5 & DNase, Motifs changed, Selected eQTL hits \\
rs2003241 (intronic) & TIMP-2 & $\mathrm{C} / T$ & $3 \mathrm{a}$ & DNase, Motifs changed, Selected eQTL hits \\
rs4789936 (5'-UTR) & TIMP-2 & T/C & $2 \mathrm{~b}$ & Motifs changed, Selected eQTL hits \\
\hline
\end{tabular}

SNP: single nucleotide polymorphism; eQTL: expression quantitative trait loci; $2 \mathrm{~b}$ : Transcription factor binding +any motif +DNase footprint + DNase peak; 3a: Transcription factor binding +any motif + DNase peak; 5: Transcription factor binding or DNase peak 
Table 3 Basic characteristics and allele frequencies of the six SNPs in the TIMP-2 gene

\begin{tabular}{|c|c|c|c|c|c|c|c|c|c|}
\hline \multirow[t]{2}{*}{ SNP } & \multirow[t]{2}{*}{ Gene } & \multirow[t]{2}{*}{ chromosome } & \multirow[t]{2}{*}{ Position } & \multirow[t]{2}{*}{ Allele } & \multicolumn{2}{|c|}{ Minor allele frequency } & \multirow{2}{*}{$\begin{array}{l}\text { HWE } p \\
\text { value }\end{array}$} & \multirow[t]{2}{*}{ OR $(95 \% \mathrm{Cl})$} & \multirow[t]{2}{*}{$p$} \\
\hline & & & & & Case & Control & & & \\
\hline rs2277698 & TIMP-2 & $17 q 25.3$ & $76,867,017$ & $\mathrm{~T} / \mathrm{C}$ & 0.201 & 0.236 & 0.0651 & $0.81(0.67-0.99)$ & 0.041 \\
\hline rs2009196 & TIMP-2 & $17 q 25.3$ & $76,870,581$ & $C / G$ & 0.392 & 0.426 & 0.3502 & $0.87(0.74-1.03)$ & 0.099 \\
\hline rs7342880 & TIMP-2 & $17 q 25.3$ & $76,874,512$ & $\mathrm{~A} / \mathrm{C}$ & 0.161 & 0.150 & 0.7433 & $1.09(0.87-1.37)$ & 0.448 \\
\hline rs11654470 & TIMP-2 & $17 q 25.3$ & $76,877,331$ & $\mathrm{C} / \mathrm{T}$ & 0.23 & 0.273 & $0.0119^{*}$ & $0.80(0.66-0.96)$ & 0.019 \\
\hline rs2003241 & TIMP-2 & $17 q 25.3$ & $76,885,117$ & $C / T$ & 0.164 & 0.161 & $0.0196^{*}$ & $1.02(0.82-1.28)$ & 0.853 \\
\hline rs4789936 & TIMP-2 & $17 q 25.3$ & $76,897,974$ & $\mathrm{~T} / \mathrm{C}$ & 0.299 & 0.307 & 0.6256 & $0.96(0.80-1.15)$ & 0.658 \\
\hline
\end{tabular}

SNP: single nucleotide polymorphism; OR: odds ratio; 95\%Cl: 95\% confidence interval; HWE: Hardy-Weinberg equilibrium ${ }^{*} p<0.05$ indicates statistical significance

Table 4 TIMP-2 SNP genotypes and the risk of breast cancer based on the results of logistic regression model analysis

\begin{tabular}{|c|c|c|c|c|c|c|}
\hline SNP & Model & Genotype & Control & Case & OR $(95 \% \mathrm{Cl})$ & $p$ \\
\hline \multirow[t]{8}{*}{ rs 2277698} & \multirow[t]{3}{*}{ Co-dominant } & CC & 329 (56.9\%) & 361 (63.3\%) & 1 & \multirow[t]{3}{*}{0.080} \\
\hline & & $\mathrm{CT}$ & 225 (38.9\%) & 189 (33.2\%) & $0.77(0.60-0.98)$ & \\
\hline & & $\pi$ & $24(4.2 \%)$ & $20(3.5 \%)$ & $0.72(0.39-1.33)$ & \\
\hline & \multirow[t]{2}{*}{ Dominant } & CC & 329 (56.9\%) & 361 (63.3\%) & 1 & \multirow[t]{2}{*}{$0.025^{*}$} \\
\hline & & $C T+T$ & 249 (43.1\%) & 209 (36.7\%) & $0.76(0.60-0.97)$ & \\
\hline & \multirow[t]{2}{*}{ Recessive } & $\mathrm{CC}+\mathrm{CT}$ & 554 (95.8\%) & 550 (96.5\%) & 1 & \multirow[t]{2}{*}{0.460} \\
\hline & & $\pi$ & $24(4.2 \%)$ & $20(3.5 \%)$ & $0.80(0.43-1.46)$ & \\
\hline & Log-additive & - & - & - & $0.80(0.65-0.98)$ & $0.029^{*}$ \\
\hline \multirow[t]{8}{*}{ rs2009196 } & \multirow[t]{3}{*}{ Co-dominant } & GG & 184 (31.9\%) & 202 (35.4\%) & 1 & \multirow[t]{3}{*}{0.190} \\
\hline & & $C G$ & 293 (50.9\%) & 290 (50.8\%) & $0.90(0.69-1.16)$ & \\
\hline & & CC & 99 (17.2\%) & 79 (13.8\%) & $0.72(0.50-1.03)$ & \\
\hline & \multirow[t]{2}{*}{ Dominant } & GG & 184 (31.9\%) & 202 (35.4\%) & 1 & \multirow[t]{2}{*}{0.210} \\
\hline & & $C G+C C$ & 392 (68.1\%) & 369 (64.6\%) & $0.85(0.67-1.09)$ & \\
\hline & \multirow[t]{2}{*}{ Recessive } & $\mathrm{GG}+\mathrm{CG}$ & 477 (82.8\%) & 492 (86.2\%) & 1 & \multirow[t]{2}{*}{0.100} \\
\hline & & $\mathrm{C} / \mathrm{C}$ & 99 (17.2\%) & 79 (13.8\%) & $0.76(0.55-1.05)$ & \\
\hline & Log-additive & - & - & - & $0.86(0.72-1.02)$ & 0.078 \\
\hline \multirow[t]{8}{*}{ rs7342880 } & \multirow[t]{3}{*}{ Co-dominant } & $\mathrm{CC}$ & 419 (72.5\%) & 399 (69.9\%) & 1 & \multirow[t]{3}{*}{0.470} \\
\hline & & $A C$ & 145 (25.1\%) & 160 (28.0\%) & $1.17(0.90-1.52)$ & \\
\hline & & AA & $14(2.4 \%)$ & $12(2.1 \%)$ & $0.90(0.41-1.97)$ & \\
\hline & \multirow[t]{2}{*}{ Dominant } & CC & 419 (72.5\%) & 399 (69.9\%) & 1 & \multirow[t]{2}{*}{0.300} \\
\hline & & $A C+A A$ & 159 (27.5\%) & 172 (30.1\%) & $1.15(0.89-1.48)$ & \\
\hline & \multirow[t]{2}{*}{ Recessive } & $C C+A C$ & $564(97.6)$ & $559(97.9)$ & 1 & \multirow[t]{2}{*}{0.710} \\
\hline & & AA & $14(2.4 \%)$ & $12(2.1 \%)$ & $0.86(0.39-1.88)$ & \\
\hline & Log-additive & - & - & - & $1.10(0.88-1.38)$ & 0.410 \\
\hline \multirow[t]{8}{*}{ rs4789936 } & \multirow[t]{3}{*}{ Co-dominant } & $\mathrm{CC}$ & 280 (48.4\%) & 280 (49.0\%) & 1 & \multirow[t]{3}{*}{0.850} \\
\hline & & $A C$ & $241(41.7 \%)$ & 241 (42.2\%) & $1.00(0.78-1.27)$ & \\
\hline & & $\mathrm{AA}$ & 57 (9.9\%) & $50(8.8 \%)$ & $0.89(0.59-1.35)$ & \\
\hline & \multirow[t]{2}{*}{ Dominant } & CC & $280(48.4 \%)$ & 280 (49.0\%) & 1 & \multirow[t]{2}{*}{0.840} \\
\hline & & $A C+A A$ & 298 (90.1\%) & 291 (51.0\%) & $0.98(0.77-1.23)$ & \\
\hline & \multirow[t]{2}{*}{ Recessive } & $C C+A C$ & $521(90.1 \%)$ & $521(91.2 \%)$ & 1 & \multirow[t]{2}{*}{0.560} \\
\hline & & AA & 57 (9.9\%) & $50(8.8 \%)$ & $0.89(0.60-1.33)$ & \\
\hline & Log-additive & - & - & - & $0.96(0.81-1.15)$ & 0.680 \\
\hline
\end{tabular}




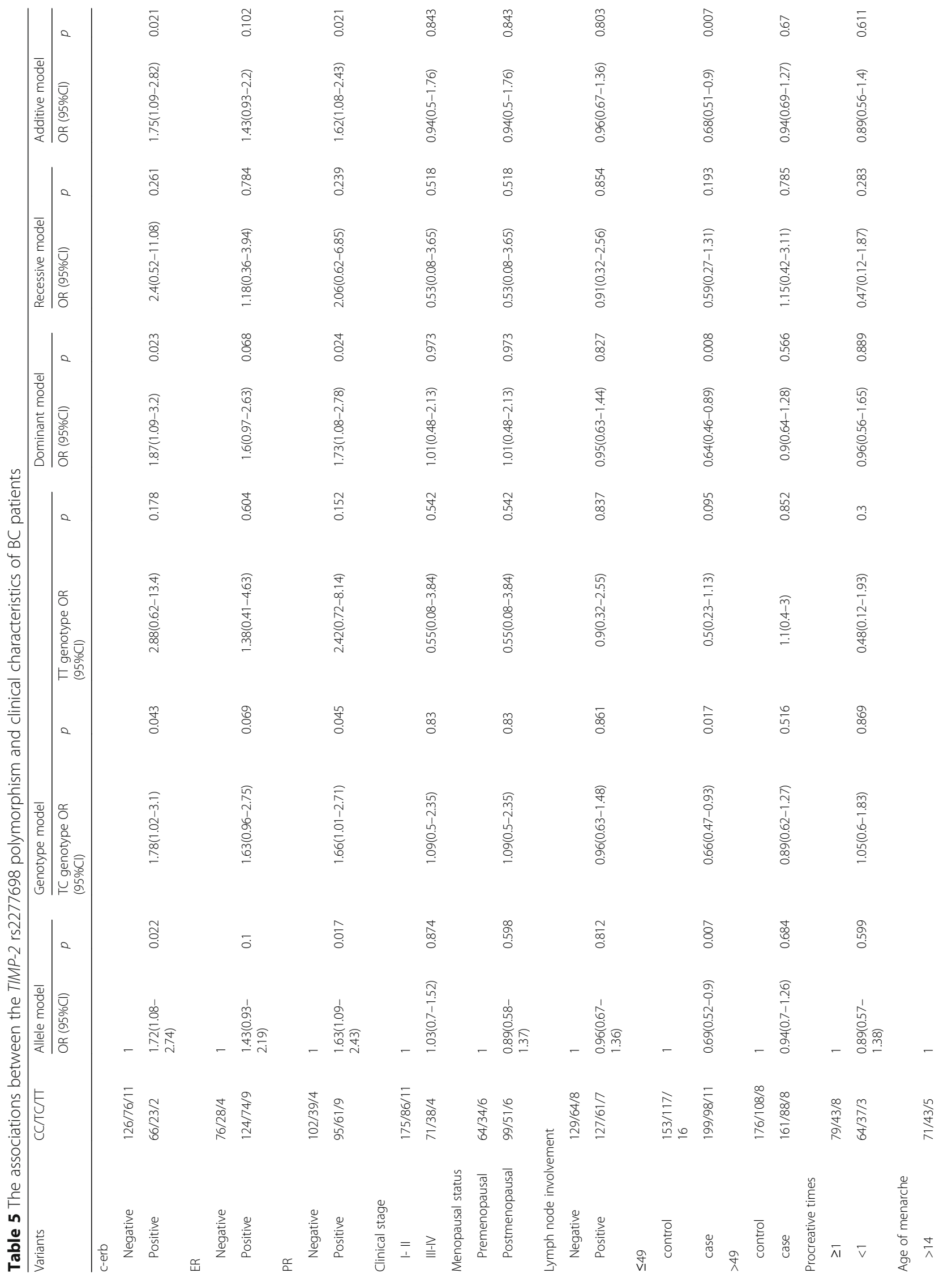




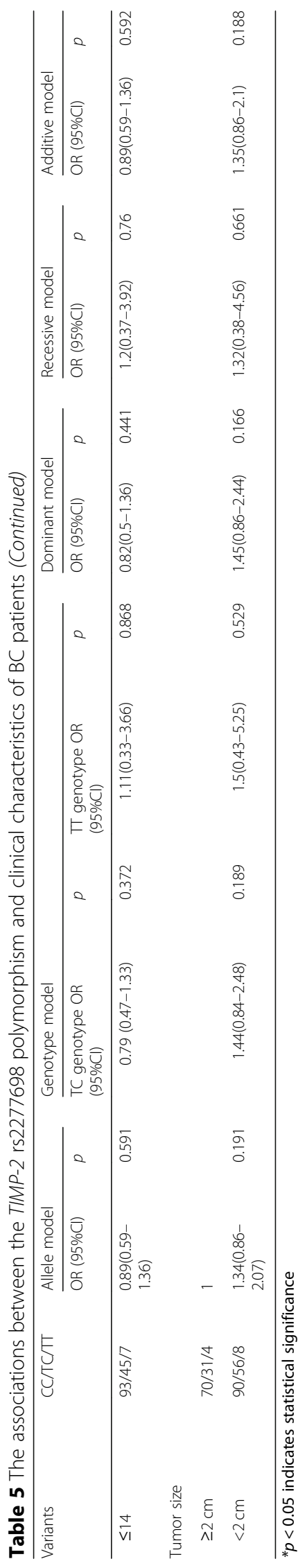




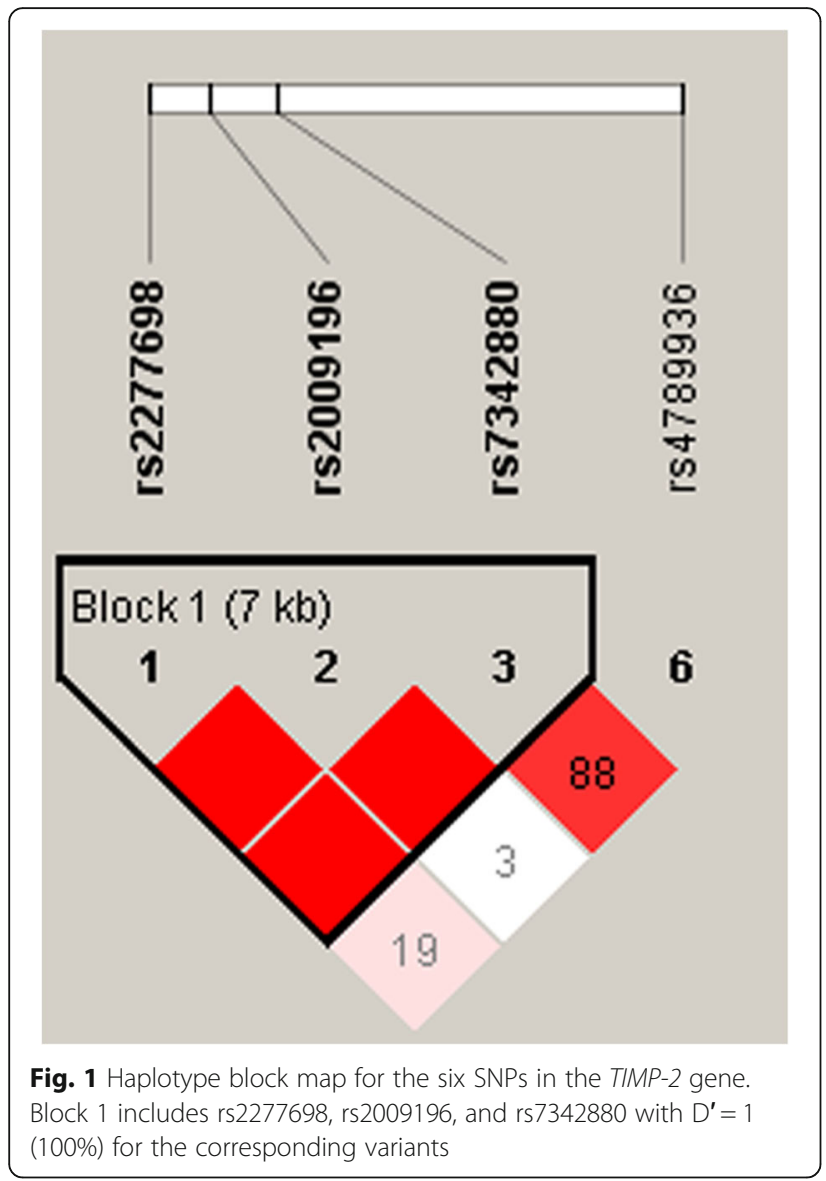

GTEx database shown that the expression level of carrying the TT genotype is higher than that of the individual carrying the CC genotype,the risk allele of rs4789936 was associated with increased expression of TIMP-2 ( $p$ $=4.1 \times 10^{-8}$ ) in peripheral blood samples (Fig. $2 \mathrm{~b}$ ).

\section{Discussion}

In this study, we found that SNP rs2277698 and haplotype, "TCC" in TIMP-2 was significantly associated with an altered risk of breast cancer. Additionally, the UALCAN database demonstrated that the TIMP-2 gene was under-expressed in breast cancer tissues. Based on the

Table 6 TIMP-2 haplotype frequencies and the association with breast cancer

\begin{tabular}{lllll}
\hline SNP & Haplotype & Freq & OR (95\%Cl) & $p$ \\
\hline rs2277698|rs2009196 & CGC & 0.591 & 1 & \\
|rs7342880 & TCC & 0.218 & $0.79(0.63-0.97)$ & $0.028^{*}$ \\
& CCA & 0.155 & $1.03(0.81-1.30)$ & 0.830 \\
& CCC & 0.036 & $0.64(0.41-1.02)$ & 0.059 \\
\hline
\end{tabular}

SNP: single nucleotide polymorphism; OR: odds ratio; $95 \% \mathrm{Cl}$ : $95 \%$ confidence interval

${ }^{*} p<0.05$ indicates statistical significance
GTEx portal, the rs4789936 risk allele "A" increased the expression of TIMP-2 in peripheral blood samples.

In the context of tumor invasion, TIMP-2 is expected to serve as an anti-invasive/anti-metastatic agent through inhibition of MMP-2. Changes in the level of TIMP-2 are known to directly affect the activity level of MMP-2 [25]. In addition, experimental evidence indicates that TIMP-2 has pleiotropic activities, including inhibition of endothelial cell growth induced by basic fibroblast growth factor, suppression of angiogenesis, and regulation of apoptosis [26]. Our analysis using the UALCAN database showed that the TIMP-2 gene was under-expressed in breast cancer tissues. A common polymorphism in the TIMP-2 gene is the $\mathrm{C}$ to $\mathrm{T}$ transition at position 303 (C303T, rs2277698), which results in a synonymous amino acid change at codon position 101 (Ser101Ser). TIMP-2 gene mutation is associated with the occurrence of multiple diseases, including alcohol induced osteonecrosis of the femoral head [27], emphysema and paraseptal emphysema [28], and gastric cancer [29]. One research explore the association between TIMP-2 and breast cancer, and found that TIMP-2 rs7501477 and rs8064344 mutation affects the genetic susceptibility of breast cancer; while, no effect of rs2277698 mutation on breast cancer was found [16]. In Korean women Primary ovarian insufficiency (POI), revealed that TIMP-2 rs817990 GC $(\mathrm{OR}=0.581)$ genotype and rs2277698 AA-GA (OR = 1.559) genotype influence the risk of Primary ovarian insufficiency in Korean women [30]. However, in our study, we only observed that rs2277698 mutation was associated with genetic susceptibility to breast cancer, and in the breast cancer patients with c-erb positive and PR positive, individuals carrying the TT genotype increased the risk of breast cancer. No other significant results were found. Combined with existing reports, we believe that rs2277698 is a susceptibility site for breast cancer, even affecting gynecological diseases. Other people reported significant results which we did not find in this study, which may be due to the false negative results caused by our small sample size. rs2277698 AA-GA (OR = 1.559) genotype influence the risk of Primary ovarian insufficiency in Korean women, while in our research our, rs2277698 “T" allele with decreased breast cancer risk, this may be due to different functions of the same locus in different diseases and genetic differences among populations. Linkage disequilibrium analysis shown that rs2277698 was strongly linked to rs9889410 and rs11654470 in the 1000 Genomes Project population $\left(\mathrm{r}^{2}>0.9\right)$, Bioinformatics analysis found that some of which (rs9889410 and rs11654470) reside in a region may be involved in changing transcriptional regulation [31]. Therefore, we speculate that rs2277698 may affect the transcription rate of TIMP-2. However, additional studies are 


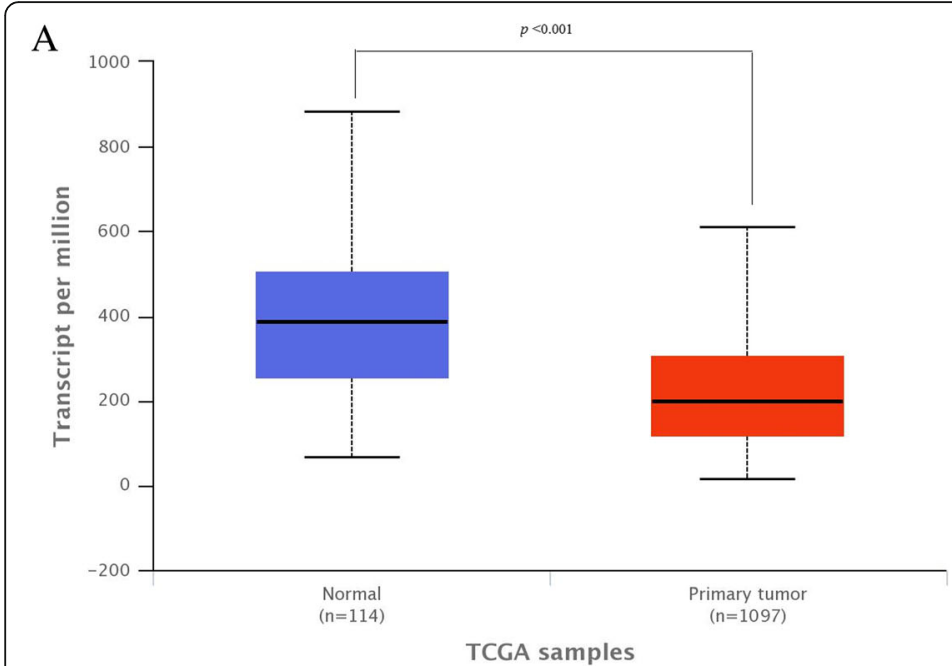

B

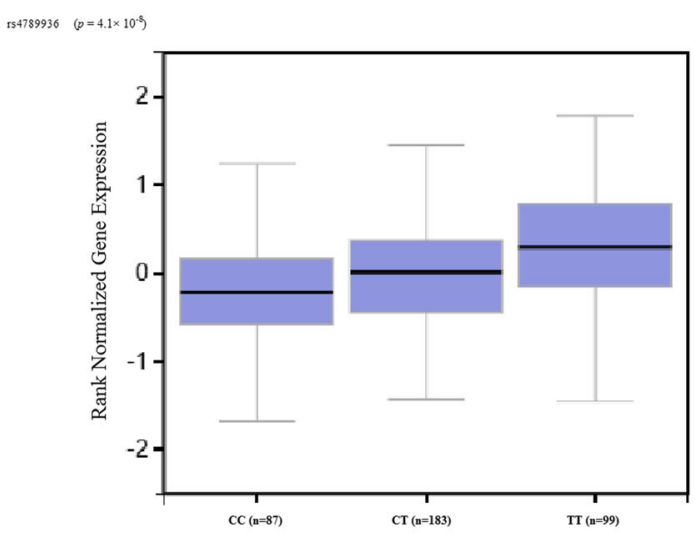

Fig. 2 Expression of TIMP-2 in human tissue databases. A: TIMP-2 gene expression is down-regulated in breast cancer $(n=1097)$ compared with normal tissues $(n=144)$. B: Expression quantitative trait loci (eQTL) analyses of rs4789936 with TIMP-2 mRNA expression levels in whole blood samples

necessary to validate these findings, and the protective mechanism of rs2277698 requires further investigation by biological means.

In our research, we found that rs7342880 and rs4789936 in TIMP-2 gene have no effect on the genetic susceptibility of breast cancer. Nevertheless, a previous study suggested that mutations in the rs4789936 locus not only affect the genetic susceptibility of breast cancer, but also affect the survival of breast cancer patients [16]. So, the role of rs4789936 mutation on the genetic susceptibility of breast cancer remains controversial. Bioinformatics analysis found that mutation of the rs4789936 locus affects the expression of the TIMP-2 gene in peripheral blood samples, the expression level of carrying the TT genotype is higher than that of the individual carrying the $\mathrm{CC}$ genotype. And, TIMP-2 was under-expressed in breast cancer tissues. So, we will first expand the sample size to verify whether mutations at this site will affect the risk of breast cancer, and further explore how mutations at this site affect breast cancer development through functional tests.

Although some clinical indicators were collected in this study and stratified analysis was performed, the sample size of complete clinical information was small, which made some indicators unable to be analyzed hierarchically, for example, obesity, smoking and drinking. We will continue to refine this information for in-depth analysis.

\section{Conclusions}

In conclusion, this study suggests that the TIMP-2 rs2277698 polymorphism is associated with breast cancer in Han Chinese women, and the individuals that carry the CT genotype and "TCC" haplotype may be at reduced risk for breast cancer. Future investigation should focus on studies using large sample sizes or establish breast cancer cell lines that further explore how mutations at this site affect breast cancer development through functional tests.

\section{Abbreviations}

95\%Cl: 95\% confidence interval; ER: estrogen receptor; GTEx: Genotype-Tissue Expression; HWE: Hardy-Weinberg equilibrium; LD: linkage disequilibrium;

OR: odds ratio; PR: progesterone receptor; SNPs: single nucleotide

polymorphisms; TIMP-2: tissue inhibitor of metalloproteinase-2

\section{Acknowledgements}

We would like to thank all the patients and individuals in this study for their participation. We are also very grateful for the assistance of the clinicians and for the hospital staff of the First Affiliated Hospital of Xi'an Jiaotong University and the Hospital of Traditional Chinese Medicine of Shaanxi province who contributed blood samples and data for this study.

\section{Funding}

Not applicable.

\section{Availability of data and materials}

Data sharing is not applicable to this article as no datasets were generated during the current study.

\section{Authors' contributions}

GW and SH collected and analyzed the patient data. AL and XJ searched and analyzed literature. GL and YZ did data interpretation. XZ did study designed. KW was a major contributor in writing the manuscript. All authors read and approved the final manuscript.

\section{Ethics approval and consent to participate}

This study was conducted under the approval of the Institutional Review Boards of both the First Affiliated Hospital of Xi'an Jiaotong University. All participants were aware of the content of the study and signed an informed consent.

Consent for publication

Not applicable. 


\section{Competing interests}

The authors declare that they have no competing interests.

\section{Publisher's Note}

Springer Nature remains neutral with regard to jurisdictional claims in published maps and institutional affiliations.

\section{Author details}

${ }^{1}$ Department of Internal Medicine Oncology, The First Affiliated Hospital of Xi'an Jiaotong University, \#277 West Yanta Road, Xi'an 710061, Shaanxi, China. ${ }^{2}$ The Second Department of Spleen and Stomach, The Hospital of Traditional Chinese Medicine of Shaanxi Province, Xi'an 710063, Shaanxi, China. ${ }^{3}$ The Second Department of Thoracic Surgery, The First Affiliated Hospital of Xi'an Jiaotong University, Xi'an 710061, Shaanxi, China. ${ }^{4}$ The Center for Medical Imaging, The Hospital of Traditional Chinese Medicine of Shaanxi Province, Xi'an 710063, Shaanxi, China.

\section{Received: 25 October 2018 Accepted: 29 April 2019}

Published online: 14 May 2019

\section{References}

1. Wieczorek E, Reszka E, Gromadzinska J, Wasowicz W. Genetic polymorphism of matrix metalloproteinases in breast cancer. Neoplasma. 2012;59(3):23747.

2. Insua-Rodriguez J, Oskarsson T. The extracellular matrix in breast cancer. Adv Drug Deliv Rev. 2016;97:41-55.

3. Saeed HM, Alanazi MS, Alshahrani O, Parine NR, Alabdulkarim HA, Shalaby MA. Matrix metalloproteinase-2 C(-1306)T promoter polymorphism and breast cancer risk in the Saudi population. Acta Biochim Pol. 2013;60(3):4059.

4. Kanayama H, Yokota K, Kurokawa Y, Murakami Y, Nishitani M, Kagawa S. Prognostic values of matrix metalloproteinase-2 and tissue inhibitor of metalloproteinase-2 expression in bladder cancer. Cancer. 2015;82(7):135966.

5. Turpeenniemi-Hujanen T. Gelatinases (MMP-2 and -9) and their natura inhibitors as prognostic indicators in solid cancers. Biochimie. 2005;87(3-4): 287-97.

6. Visse R, Nagase H. Matrix metalloproteinases and tissue inhibitors of metalloproteinases: structure, function, and biochemistry. Circ Res. 2003; 92(8):827-39.

7. Srivastava P, Lone TA, Kapoor R, Mittal RD. Association of promoter polymorphisms in MMP2 and TIMP2 with prostate cancer susceptibility in North India. Arch Med Res. 2012;43(2):117-24.

8. Vairaktaris E, Yapijakis C, Yiannopoulos A, Vassiliou S, Serefoglou Z Vylliotis A, Nkenke E, Derka S, Critselis E, Avgoustidis D, et al. Strong association of the tissue inhibitor of metalloproteinase-2 polymorphism with an increased risk of oral squamous cell carcinoma in Europeans. Oncol Rep. 2007;17(4):963-8.

9. Yaykasli KO, Kayikci MA, Yamak N, Soguktas H, Duzenli S, Arslan AO, Metin A, Kaya E, Hatipoglu OF. Polymorphisms in MMP-2 and TIMP-2 in Turkish patients with prostate cancer. Turk J Med Sci. 2014:44(5):839-43.

10. Mikolajczyk-Stecyna J, Korcz A, Gabriel M, Pawlaczyk K, Oszkinis G, Slomski R. Gene polymorphism $-418 \mathrm{G} / \mathrm{C}$ of tissue inhibitor of metalloproteinases 2 is associated with abdominal aortic aneurysm. J Vasc Surg. 2015;61(5):1114-9.

11. $\mathrm{P}$ OC, Khantapura $\mathrm{P}$. The role of genetic polymorphisms in the promoters of the matrix metalloproteinase-2 and tissue inhibitor of metalloproteinase-2 genes in head and neck cancer. Oral Oncol. 2006:42(3):257-67.

12. Zhang DY, Wang J, Zhang GQ, Chu XQ, Zhang JL, Zhou Y. Correlations of MMP-2 and TIMP-2 gene polymorphisms with the risk and prognosis of gastric cancer. Int J Clin Exp Med. 2015;8(11):20391-401.

13. Guo T, Hao H, Zhou L, Zhou F, Yu D. Association of SNPs in the TIMP-2 gene and large artery atherosclerotic stroke in southern Chinese Han population. Oncotarget. 2018;9(4):4698-706.

14. Wang K, Zhou Y, Li G, Wen X, Kou Y, Yu J, He H, Zhao Q, Xue F, Wang J, et al. MMP8 and MMP9 gene polymorphisms were associated with breast cancer risk in a Chinese Han population. Sci Rep. 2018:8(1):13422.

15. Jin T, Cao W, Zuo X, Li M, Yang Y, Liang T, Yang H, Zhao X, Yang D. IL-1RN gene polymorphisms are associated with breast cancer risk in a Chinese Han population. The journal of gene medicine. 2017;19(12).
16. Peterson NB, Beeghly-Fadiel A, Gao YT, Long J, Cai Q, Shu XO, Zheng W. Polymorphisms in tissue inhibitors of metalloproteinases- 2 and -3 and breast cancer susceptibility and survival. Int J Cancer. 2009;125(4):844-50.

17. Gabriel S, Ziaugra L, Tabbaa D: SNP genotyping using the Sequenom MassARRAY iPLEX platform. Current protocols in human genetics 2009, Chapter 2:Unit 2.12

18. Thomas RK, Baker AC, Debiasi RM, Winckler W, Laframboise T, Lin WM, Wang M, Feng W, Zander T, MacConaill L, et al. High-throughput oncogene mutation profiling in human cancer. Nat Genet. 2007;39(3):347-51.

19. Boyle AP, Hong EL, Hariharan M, Cheng Y, Schaub MA, Kasowski M, Karczewski KJ, Park J, Hitz BC, Weng S, et al. Annotation of functional variation in personal genomes using RegulomeDB. Genome Res. 2012;22(9): 1790-7.

20. Ward LD, Kellis M. HaploReg v4: systematic mining of putative causal variants, cell types, regulators and target genes for human complex traits and disease. Nucleic Acids Res. 2016;44(D1):D877-81.

21. Chandrashekar DS, Bashel B, Balasubramanya SAH, Creighton CJ, PonceRodriguez I, Chakravarthi B, Varambally S. UALCAN: a portal for facilitating tumor subgroup gene expression and survival analyses. Neoplasia. 2017; 19(8):649-58.

22. Adamec $C$. Example of the use of the nonparametric test. Test $\mathrm{X} 2$ for comparison of 2 independent examples. Ceskoslovenske zdravotnictvi. 1964; 12:613-9.

23. Bland JM, Altman DG. Statistics notes. The odds ratio. BMJ. 2000;320(7247): 1468

24. Barrett JC, Fry B, Maller J, Daly MJ. Haploview: analysis and visualization of LD and haplotype maps. Bioinformatics. 2005;21(2):263-5.

25. Remacle A, McCarthy K, Noel A, Maguire T, McDermott E, O'Higgins N, Foidart JM, Duffy MJ. High levels of TIMP-2 correlate with adverse prognosis in breast cancer. Int J Cancer. 2000;89(2):118-21.

26. Gakiopoulou H, Nakopoulou L, Siatelis A, Mavrommatis I, Panayotopoulou EG, Tsirmpa I, Stravodimos C, Giannopoulos A. Tissue inhibitor of metalloproteinase-2 as a multifunctional molecule of which the expression is associated with adverse prognosis of patients with urothelial bladder carcinomas. Clinical cancer research : an official journal of the American Association for Cancer Research. 2003;9(15):5573-81.

27. Chen J, Guo Y, Jin T, Li J, Du J, Cao Y, Wang J. Association of MMPs/TIMPs polymorphism with alcohol-induced osteonecrosis of femoral head in the Chinese Han population; 2016.

28. Kukkonen MK, Tiili E, Vehmas T, Oksa P, Piirila P, Hirvonen A. Association of genes of protease-antiprotease balance pathway to lung function and emphysema subtypes. BMC Pulm Med. 2013;13:36.

29. Park KS, Kim SJ, Kim KH, Kim JC. Clinical characteristics of TIMP2, MMP2, and MMP9 gene polymorphisms in colorectal cancer. J Gastroenterol Hepatol. 2011;26(2):391-7.

30. An HJ, Ahn EH, Kim JO, Park HS, Ryu CS, Cho SH, Kim JH, Lee WS, Kim NK. Association between tissue inhibitor of metalloproteinase (TIMP) genetic polymorphisms and primary ovarian insufficiency (POI). Maturitas. 2019;120:77-82.

31. Lee PH, Shatkay H. F-SNP: computationally predicted functional SNPs for disease association studies. Nucleic Acids Res. 2008;36(Database issue): D820-4.

Ready to submit your research? Choose BMC and benefit from:

- fast, convenient online submission

- thorough peer review by experienced researchers in your field

- rapid publication on acceptance

- support for research data, including large and complex data types

- gold Open Access which fosters wider collaboration and increased citations

- maximum visibility for your research: over $100 \mathrm{M}$ website views per year

At $\mathrm{BMC}$, research is always in progress.

Learn more biomedcentral.com/submissions 